\title{
Pharmacokinetics and Tolerability of the Novel Oral Prostacyclin IP Receptor Agonist Selexipag
}

\author{
Priska Kaufmann $^{1} \cdot$ Kaori Okubo $^{2} \cdot$ Shirin Bruderer $^{1} \cdot$ Tim Mant $^{3}$ • \\ Tetsuhiro Yamada $^{2} \cdot$ Jasper Dingemanse $^{1} \cdot$ Hideya Mukai $^{2}$
}

Published online: 8 April 2015

(c) The Author(s) 2015. This article is published with open access at Springerlink.com

\begin{abstract}
Purpose Targeting the prostacyclin pathway is an effective treatment option for pulmonary arterial hypertension (PAH). Patients with PAH have a deficiency of prostacyclin and prostacyclin synthase. Selexipag is an orally available and selective prostacyclin receptor (IP receptor) agonist. Selexipag is hydrolyzed to its active metabolite ACT-333679, also a selective and potent agonist at the IP receptor.

Methods In this phase I study the pharmacokinetics (PK) and tolerability of single and multiple ascending doses of selexipag were investigated in a double-blind, placebocontrolled manner in 64 healthy male subjects. An additional group of 12 subjects received an open-label dose of selexipag $400 \mu \mathrm{g}$ in the fasted condition and after a meal. Results Maximum plasma concentrations of selexipag and ACT-333679 were reached within 2.5 and $4 \mathrm{~h}$, respectively, with mean half-lives of 0.7-2.3 and 9.4-14.22 h. In the presence of food, exposure to ACT333679 was decreased by $27 \%$. The most frequent adverse event was headache. Selexipag was well tolerated up to a single dose of $400 \mu \mathrm{g}$ and multiple doses of $600 \mu \mathrm{g}$ following an up-titration step. No relevant treatment-related effects on vital signs, clinical laboratory, and electrocardiogram (ECG) parameters were detected.

Conclusion Selexipag exhibits a good tolerability profile and PK properties that warrant further investigation.
\end{abstract}

Priska Kaufmann

priska.kaufmann@actelion.com

1 Department of Clinical Pharmacology, Actelion Pharmaceuticals Ltd, Gewerbestrasse 16, 4123 Allschwil, Switzerland

2 Nippon Shinyaku, Kyoto, Japan

3 Quintiles Drug Research Unit, Guy's Hospital, London, UK

\section{Key Points}

Orally administered selexipag is in development for the treatment of pulmonary arterial hypertension (PAH). Selexipag targets the prostacyclin pathway, one of the key pathways involved in the pathology of PAH.

In this phase I study, selexipag was well tolerated in healthy male subjects receiving both single oral doses up to $400 \mu \mathrm{g}$ and multiple oral doses of twicedaily $600 \mu \mathrm{g}$ (following up-titration from $400 \mu \mathrm{g}$ ).

Tolerability was improved when the drug was uptitrated in steps.

The drug pharmacokinetic profile supports that selexipag should be taken twice daily with food.

\section{Introduction}

Pulmonary arterial hypertension (PAH) is a hemodynamic and pathophysiological condition affecting the pulmonary arterioles and characterized by progressive increases in pulmonary vascular resistance and pulmonary artery pressure, ultimately leading to right heart failure and premature death $[1,2]$. Recent therapeutic options have significantly improved the long-term outcome of patients with $\mathrm{PAH}$, but $\mathrm{PAH}$ remains a disease with a poor prognosis [3-5].

Reduced expression of prostacyclin synthases in the lung and reduced levels of prostacyclin are key features of PAH [6-8]. Prostacyclin is produced by endothelial cells from prostaglandin $\mathrm{H} 2$ (PGH2) by the enzyme prostacyclin 
synthase [6]. Prostacyclin is a potent vasodilator and also has anti-proliferative, antithrombotic, and anti-inflammatory effects $[8,9]$. As PAH is associated with vasoconstriction, proliferation, and thrombosis, there is a strong rationale for using prostacyclin treatment $[1,2,10]$. Restoration of IP receptor signaling using prostacyclin receptor (IP receptor) agonists is an effective strategy in the treatment of the disease.

Although beneficial effects of prostacyclins such as epoprostenol have been documented, their clinical application remains cumbersome due to limited stability and a very short half-life of 3-5 $\min$ [11] as well as the need for continuous intravenous (IV) infusion. Complex delivery systems are required that are associated with adverse and potentially serious complications. These may hamper dose titration and may lead to discontinuation of treatment [12, 13]. Epoprostenol was the first targeted PAH therapy to be approved, and improved the prognosis of patients with PAH $[11,14,15]$. Several prostacyclin analogs have been synthesized since, with different modes of application, including subcutaneous, inhaled, and oral. Alternatives to epoprostenol include treprostinil and iloprost in the USA and some European countries and beraprost in Japan and Korea.

Selexipag (previously known as NS-304 or ACT293987) (Fig. 1) is a novel orally available selective IP receptor agonist. Selexipag is rapidly absorbed after oral administration and hydrolyzed to the pharmacologically more active metabolite ACT-333679 (previously known as MRE-269) [16]. ACT-333679 is considered as the major contributor to the overall activity of the drug. A single-dose

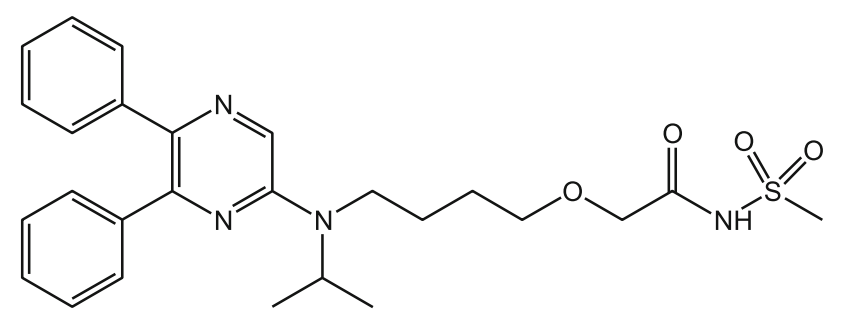

Selexipag

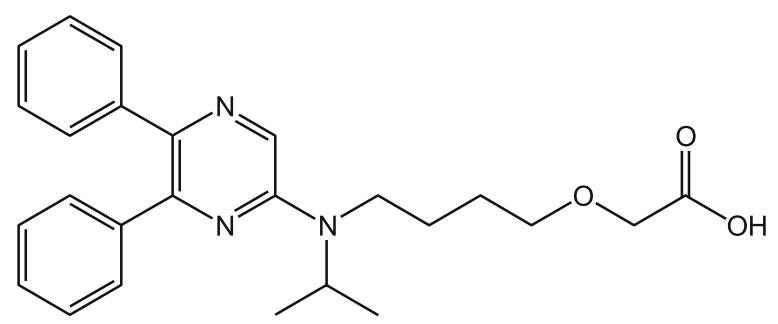

ACT-333679

Fig. 1 Chemical structures of selexipag and its metabolite ACT333679 study of oral selexipag $(100 \mu \mathrm{g})$ conducted in five healthy male subjects showed that it was metabolized to ACT333679, which has an elimination half-life in the human body of $7.9 \mathrm{~h} \mathrm{[17].} \mathrm{Although} \mathrm{it} \mathrm{acts} \mathrm{through} \mathrm{the} \mathrm{prostacy-}$ clin pathway, selexipag is chemically distinct from prostacyclin analogs and has a high selectivity for the human IP receptor over other receptors [17].

The aim of the present study was to assess the pharmacokinetics (PK) of single ascending doses (SAD) and multiple ascending doses (MAD) of selexipag in healthy male subjects. In addition, the effect of food on PK and tolerability was evaluated.

\section{Methods}

\subsection{Subjects}

The protocol was approved by the Research Ethics Committee at St Thomas' Hospital (London, UK). Written informed consent was obtained from all subjects. The study was conducted in full compliance with the principles of the Declaration of Helsinki and with laws and regulations of the UK, where the research study was conducted. The Medicine and Health Care Products Regulatory Agency (MHRA) of the UK reviewed and approved the study before any activity commenced.

The study population included non-smoking healthy male subjects of any ethnic origin aged between 18 and 45 years, with a body mass index (BMI) between 19 and $30 \mathrm{~kg} / \mathrm{m}^{2}$. Subjects were assessed to be healthy on the basis of screening examinations. For recruitment, the subjects were to have normal physical examination findings, vital signs, laboratory values, and 12-lead electrocardiogram (ECG) results during screening, as well as no history or evidence of alcohol or drug abuse. Subjects who reported the use of another investigational drug, smoking, or donation of blood within 3 months prior to first dosing were excluded from the study.

\subsection{Study Design}

The SAD and MAD studies were double-blind, randomized, placebo-controlled, dose-escalation phase I studies evaluating the safety, tolerability, and PK of selexipag and ACT-333679, whereas the food effect was evaluated in an open-label, randomized, two-period crossover study.

Subjects who were deemed eligible (based on screening, inclusion and exclusion criteria) were admitted to the site in the evening of the day before the start of treatment (Day 1). They were tested for any evidence of consumption or abuse of alcohol or drugs and were assigned the randomization code number for the corresponding study 
treatment group. Within each group of the SAD and MAD part, subjects were randomly allocated to selexipag or placebo. Dose escalation to the next treatment group was performed following satisfactory review of the safety and tolerability of the preceding dose groups.

In the SAD study, subjects were enrolled: eight subjects each participated in one of five treatment groups $(100,200$, 400,600 , and $800 \mu \mathrm{g}$ dose groups), in which six and two subjects per dose group were randomized to active medication and placebo, respectively. In all dose groups, subjects received the study drug in the fasted state in the morning of treatment Day 1. The subjects remained under observation at the study site for $48 \mathrm{~h}$ after administration of the study drug and were discharged after all study assessments were completed (i.e., in the morning of Day 3). A post-treatment follow-up visit was performed on Day 7 for adverse event (AE) review, medical history update, and clinical laboratory safety tests. The dose used to study the food effect was selected based on the safety and tolerability results of the SAD study. In period 1, a total of 12 subjects received a single dose of $400 \mu \mathrm{g}$ after an overnight fast of at least $10 \mathrm{~h}$ or following a high-fat breakfast given $30 \mathrm{~min}$ pre-dose [18]. In period 2, the same subjects received the study medication in the alternative condition to period 1 . The dosing in both periods was separated by at least 7 days. The subjects remained under observation at the study site for $48 \mathrm{~h}$ after administration of the study drug. A post-treatment follow-up visit was performed on Day 7 for AE review, medical history update, and clinical laboratory safety tests.

In the MAD study, 24 healthy male subjects were studied in three groups of eight subjects each (six receiving active drug and two receiving placebo) in one of three treatment groups $(200 \mu \mathrm{g}, 400 \mu \mathrm{g}$, up-titration scheme from 400 to $600 \mu \mathrm{g}$ dose groups). In the morning of Day 1, a single oral dose of selexipag or placebo was administered; no study drug was administered on Day 2. On Days 3-7, treatment was twice daily, followed by a single dose of selexipag or placebo in the morning of Day 8. Subjects in the 400/600 $\mu \mathrm{g}$ up-titration group received a single oral dose of selexipag $400 \mu \mathrm{g}$ or placebo in the morning of Day 1. No study drug was administered on Day 2. Subsequently, on Days 3-4, selexipag $400 \mu \mathrm{g}$ or placebo was administered twice daily, followed by selexipag $600 \mu \mathrm{g}$ or placebo twice daily on Days 5-7, and then a single dose of selexipag $600 \mu \mathrm{g}$ or placebo in the morning of Day 8. All doses were administered within 5 min after breakfast or dinner. Based on the results of the food-effect study, investigators decided to administer selexipag in the MAD part of the study in the fed state. Subjects resided at the study site until the morning of Day 10 (48 h after last dose). A follow-up visit for AE review, medical history update, and clinical laboratory safety tests was performed on Day 17.

\subsection{Safety and Tolerability}

Subjects were monitored for safety and tolerability throughout the study. Assessments were based on recording of AEs as well as physical examination, vital signs, ECGs, and clinical laboratory tests, performed at screening and periodically after dosing.

\subsection{Sample Collection and Bio-Analysis}

Plasma and urine samples were collected for measurement of selexipag and ACT-333679 concentrations. Validated liquid chromatography coupled to tandem mass spectrometry (LC-MS/MS) assays specific for measurement of the unchanged compound as well as the metabolite were used. The lower limit of quantification (LLOQ) was $0.01 \mathrm{ng} / \mathrm{ml}$ for both analytes in plasma and urine.

To $600 \mu \mathrm{l}$ of acidified plasma (containing $10 \%$ of $1 \mathrm{M}$ hydrochloric acid) or acidified urine, $50 \mu \mathrm{l}$ of internal standard solution (MRE-282, methanol as solvent), $500 \mu \mathrm{l}$ of $1 \%$ formic acid, and $50 \mu \mathrm{l}$ of methanol were added. The samples were loaded onto a solid-phase extraction cartridge (OASIS HLB $60 \mathrm{mg} / 3 \mathrm{cc}$, Waters Corporation, Milford, MA, USA), washed, and eluted with methanol $6 \mathrm{ml}$. After evaporation of eluted solutions under a stream of nitrogen gas heated to a maximum temperature of $40{ }^{\circ} \mathrm{C}$, the residues were reconstituted in $200 \mu \mathrm{l}$ of solvent (ultrapure water and methanol mixed in a 50:50 ratio), centrifuged $\left(12,000 \mathrm{rpm}, 2 \mathrm{~min}, 4{ }^{\circ} \mathrm{C}\right)$, and $20 \mu \mathrm{l}$ of the supernatant was injected onto the LC-MS/MS. The chromatographic system consisted of a pump, a column (Develosil C30-UG-5 $2 \mathrm{~mm} \times 150 \mathrm{~mm}, 5 \mu \mathrm{m}$ particle size, Nomura Chemical Co. Ltd., Seto, Japan), and a guard filter (Rheodyne Column Inlet Filter $3 \mathrm{~mm}$ diameter frit Rheodyne, Co. Ltd, Rohnert Park, CA, USA). Mobile phases consisted of methanol/formic acid $0.1 \%$ $(85: 15 \mathrm{vol} / \mathrm{vol})$. Mass spectrometric detection was performed with a turbo ion spray operating in positive-ion mode at $600{ }^{\circ} \mathrm{C}$. Samples were quantified using peak area ratios.

Quality control (QC) samples were analyzed, and their measured concentrations were used to determine betweenrun, overall precision, and accuracy of the analyses. The inter-batch coefficients of variation of QC samples were between 3.7 and $12.2 \%$ for selexipag and between 3.9 and $10.6 \%$ for ACT-333679, whereas the inter-batch accuracies were in the range of $97.5-107.9 \%$ for selexipag and 95.2-102.0\% for ACT-333679.

In the SAD and the food-effect studies, blood samples were collected into lithium-heparin tubes on Day 1 prior to dosing, and at $0.25,0.5,1,1.5,2,2.5,3,4,6,8,12,16,24$, 36 , and $48 \mathrm{~h}$ post-dose. A similar schedule of blood sampling was applied in the MAD study for Day 1 and 2 (first 
36 h post-dose only) and on Day 8-10, whereas blood was sampled every morning immediately before dosing between Days 3 and 7. Within 30 min of collection, blood samples were centrifuged, plasma was transferred into new polypropylene tubes, and $10 \%$ of $1 \mathrm{M}$ hydrochloric acid was added. All samples were stored in an upright position at $-20{ }^{\circ} \mathrm{C}$ or below.

Urine samples were collected into polyethylene containers over the following time intervals: pre-dose, $0-12$, 12-24, and 24-48 h post-dose for the SAD study and 0-48 h post-dose on Day 1 and Day 8 for the MAD study. Hydrochloric acid $(100 \mathrm{ml}$ of $1.0 \mathrm{M} \mathrm{HCl})$ was added to each container before urine collection commenced. During each collection period, the contents were stored in a refrigerator at approximately $4{ }^{\circ} \mathrm{C}$. At the end of each collection period, the total volume was measured, and urine aliquots were stored at approximately $-20{ }^{\circ} \mathrm{C}$.

\subsection{Data Analysis and Statistical Results}

Pharmacokinetic analyses were performed to determine the plasma PK parameters and the total excretion of selexipag and ACT-333679 in urine. Individual plasma concentrations were analyzed using WinNonLin ${ }^{\circledR} 4$.1.b software and the PK parameters per subject were derived.

Dose proportionality was assessed for selexipag and ACT-333679 across doses for maximum plasma concentration $\left(C_{\max }\right)$ and area under plasma concentration-time curve from 0 to infinity $\left(\mathrm{AUC}_{0-\infty}\right)$ or $\mathrm{AUC}_{\tau}$ values using a power model [19]. A point estimate and $95 \%$ confidence interval (CI) were produced for the population mean slope. Non-dose proportionality was established if the $95 \%$ CI for the slope excluded 1.

The effect of food on the PK of a single dose of selexipag $400 \mu \mathrm{g}$ was investigated using a mixed-effects analysis of variance model, with fixed-effect terms for sequence, treatment, and period and a random effect for subject, which was fitted to the data using PROC MIXED in the statistical package SAS. The primary PK parameters $C_{\max }$ and $\mathrm{AUC}_{0-\infty}$ of selexipag and ACT-333679 were logarithmically transformed prior to statistical analysis.

The $90 \% \mathrm{CI}$ of the ratio of geometric means for the variables $C_{\max }$ and $\mathrm{AUC}_{0-\infty}$ was calculated comparing fed versus fasted. No effect of food was concluded when the $90 \%$ CI was entirely within the bioequivalence interval of $0.80-1.25$.

Concentrations below the LLOQ prior to $C_{\max }$ were taken as zero, and those observed after $C_{\max }$ were excluded from the analysis.

Statistical Analysis System $\left(\mathrm{SAS}^{\circledR}\right)$ software, version 8.2 (SAS Institute, Cary, NC, USA) was used for all statistical analysis.

\section{Results}

\subsection{Demographics and Baseline Characteristics}

In the SAD study, 40 healthy male subjects were randomized (29 Caucasian, six Black, three Asian, one Hispanic, and one 'other'). The age range was 19-44 years, and the BMI was $21-30 \mathrm{~kg} / \mathrm{m}^{2}$.

In the MAD study, 24 healthy male subjects aged between 18 and 34 years (22 Caucasian, two Asian) were enrolled, with a BMI of $20-30 \mathrm{~kg} / \mathrm{m}^{2}$.

In the food-effect study, 12 healthy subjects (seven Caucasian, three Asian, one Hispanic, and one Black) aged between 19 and 44 years were enrolled, with a BMI of $19-27 \mathrm{~kg} / \mathrm{m}^{2}$.

All except two subjects completed the study. One subject within the food-effect study discontinued the study prematurely as a result of increased liver enzymes of less than two times the upper limit of normal, probably due to alcohol intake during the washout period. This subject was not replaced. A subject in the MAD study, who withdrew consent post-dose on Day 1, was replaced.

\subsection{Safety and Tolerability}

Across all three studies, a total of 113 treatment-emergent AEs were reported by 43 of the 77 subjects included in the safety analysis. Overall, the most frequently reported AE was headache. Selexipag was well tolerated in the SAD study at the 100, 200, and $400 \mu \mathrm{g}$ dose levels, at all dose levels in the MAD study, and in the food-effect study. AEs occurred with increasing frequency and intensity at single doses beyond $400 \mu \mathrm{g}$.

No clinically relevant effects of treatment with selexipag on mean clinical laboratory parameters, ECG recordings, physical examination, and vital sign values were observed. No AEs related to clinical laboratory variables, ECG recordings, or physical examination were recorded. There were no serious AEs. The majority of AEs resolved spontaneously without sequelae. One incident of procedural site reaction, rash, and nasal congestion in the MAD study had not resolved at follow-up. Summaries of the AEs reported during the SAD and MAD parts of the study, including those AEs judged to be unrelated to study drug, are provided in Tables 1 and 2 .

In the SAD study, 16 of the 40 subjects reported AEs, 12 (40\%) subjects after administration of selexipag and four (40\%) subjects after administration of placebo. The most frequent treatment-emergent $\mathrm{AE}$ was headache, with nine subjects across the different selexipag dose groups, and none in the placebo group. Six subjects reported nausea: five subjects within the 600 and $800 \mu \mathrm{g}$ dose groups and 
Table 1 Summary of treatment-emergent adverse events (including unrelated) by frequency (fasted) reported by two or more subjects following single ascending doses

\begin{tabular}{|c|c|c|c|c|c|c|c|}
\hline \multirow[t]{2}{*}{ Group: all subjects } & \multicolumn{7}{|c|}{ Treatment (selexipag/placebo) } \\
\hline & $100 \mu \mathrm{g}$ & $200 \mu \mathrm{g}$ & $400 \mu \mathrm{g}$ & $600 \mu \mathrm{g}$ & $800 \mu \mathrm{g}$ & Total selexipag & Placebo \\
\hline$n$ & 6 & 6 & 6 & 6 & 6 & 30 & 10 \\
\hline \multicolumn{8}{|l|}{ All system organ classes } \\
\hline Total subjects with at least one $\mathrm{AE}$ & 1 & 1 & 0 & 4 & 6 & 12 & 4 \\
\hline Total number of AEs & 2 & 2 & 0 & 12 & 17 & 33 & 7 \\
\hline Headache & 1 & 1 & - & 2 & 5 & 9 & - \\
\hline Nausea & - & - & - & 2 & 3 & 5 & 1 \\
\hline Vomiting & - & - & - & 1 & 3 & 4 & - \\
\hline Dizziness & 1 & - & - & - & 2 & 3 & - \\
\hline Dizziness postural & - & 1 & - & 1 & 1 & 3 & 1 \\
\hline
\end{tabular}

Only AEs with onset after start of treatment are included

$A E(s)$ adverse event(s)

Table 2 Summary of treatment-emergent adverse events (including unrelated events) by frequency (fasted) reported by two or more subjects following multiple ascending doses

\begin{tabular}{llllll}
\hline Group: all subjects & \multicolumn{5}{l}{ Treatment (selexipag/placebo) } \\
\cline { 2 - 6 } & $200 \mu \mathrm{g}$ & $400 \mu \mathrm{g}$ & $400 / 600 \mu \mathrm{g}$ & Total selexipag & Placebo \\
\hline$n$ & 6 & 6 & 7 & 19 & 6 \\
All system organ classes & & & & & \\
Total subjects with at least one AE & 5 & 5 & 5 & 15 & 5 \\
Total number of AEs & 15 & 26 & 15 & 56 & 10 \\
Headache & 3 & 4 & 3 & 10 & 1 \\
Procedural site reaction & 1 & 3 & 2 & 6 & 1 \\
Dizziness & 1 & 1 & 2 & 4 & 1 \\
Somnolence & 2 & 2 & - & 4 & - \\
Cough & - & 1 & 1 & 2 & 1 \\
Pharyngolaryngeal pain & - & 1 & 1 & 2 & - \\
Nausea & - & 1 & 1 & 2 & 1 \\
Rhinitis & - & 1 & 1 & 2 & - \\
Feeling abnormal & - & 2 & - & 2 & 1 \\
\hline
\end{tabular}

200 and $400 \mu \mathrm{g}$ group: subjects received selexipag/placebo once daily on Day 1, twice daily on Days 3-7 and once daily on Day 8. 400/600 $\mu \mathrm{g}$ group = Day 1, 3, 4 at $400 \mu \mathrm{g}$; Days 5-8 at $600 \mu \mathrm{g}$

$A E(s)$ adverse event(s) one in the placebo group. The incidence and intensity increased at doses higher than $400 \mu \mathrm{g}$. All subjects who received selexipag $800 \mu \mathrm{g}$ reported at least one AE.

Selexipag was well tolerated by the subjects participating in the food study. Nine treatment-emergent AEs were reported by six of the 12 subjects. Two subjects (17\%) reported AEs in the fed period and five subjects $(45 \%)$ in the fasted period. One subject was withdrawn before period 2 dosing because of increased hepatic enzymes of less than two times the upper limit of normal, probably due to alcohol consumption during the washout period.

Multiple doses of selexipag were well tolerated at the 200,400 , and $400 \mu \mathrm{g} / 600 \mu \mathrm{g}$ dose levels. A total of 66 treatment-emergent AEs were reported by 20 of the 25 subjects, of whom 15 (79\%) received selexipag and five $(83 \%)$ received placebo. There was no consistent trend in the number of AEs with increasing doses of selexipag, and the incidence of AEs per subject was similar for all treatment groups.

\subsection{Plasma Pharmacokinetics}

The PK parameters determined in the SAD and MAD study are reported in Tables 3 and 4, respectively.

Following single oral administration of selexipag under fasted conditions, peak plasma concentrations were achieved within $2 \mathrm{~h}$, with no concentrations above $15.66 \mathrm{ng} / \mathrm{ml}$. The mean plasma concentration-time profiles 
Table 3 Pharmacokinetic parameters of selexipag and ACT-333679 in healthy male subjects after a single oral dose of selexipag $100-800 \mu \mathrm{g}$ in the fasted state

\begin{tabular}{llllll}
\hline Dose $(\mu \mathrm{g})$ & $n$ & $C_{\max }(\mathrm{ng} / \mathrm{ml})$ & $t_{\max }(\mathrm{h})$ & $\mathrm{AUC}_{0-\infty}(\mathrm{ng} \cdot \mathrm{h} / \mathrm{ml})$ & $t_{1 / 2}(\mathrm{~h})$ \\
\hline $\begin{array}{l}\text { Selexipag } \\
100\end{array}$ & 6 & $2.20(1.42-3.52)$ & $1.26(1.0-1.5)$ & $4.61(3.0-8.3)$ & $0.7(0.7-0.9)$ \\
200 & 6 & $3.40(1.98-7.98)$ & $1.00(1.0-1.5)$ & $6.77(4.5-14.9)$ & $0.8(0.7-1.0)$ \\
400 & 6 & $5.98(3.86-10.40)$ & $1.00(1.0-1.5)$ & $12.35(7.6-20.5)$ & $1.0(0.8-1.9)$ \\
600 & 6 & $11.19(7.16-15.66)$ & $1.00(1.0-2.0)$ & $23.27(19.7-27.2)$ & $1.9(0.7-2.8)$ \\
800 & 6 & $11.53(9.45-14.81)$ & $1.00(0.5-1.5)$ & $24.97(18.1-35.3)$ & $2.3(1.0-3.4)$ \\
ACT-333679 & & & & & \\
100 & 6 & $1.99(1.51-2.44)$ & $2.50(2.0-4.0)$ & $12.60(9.1-15.5)$ & $9.8(8.1-12.2)$ \\
200 & 6 & $4.10(2.78-5.36)$ & $2.75(2.0-4.0)$ & $26.33(19.3-36.4)$ & $12.6(11.5-15.6)$ \\
400 & 6 & $8.18(4.50-15.64)$ & $2.25(2.0-4.0)$ & $53.65(30.7-125.9)$ & $9.8(8.5-11.3)$ \\
600 & 6 & $12.47(10.08-16.10)$ & $2.50(2.0-4.0)$ & $78.85(59.5-121.5)$ & $9.4(8.5-11.5)$ \\
800 & 6 & $14.37(10.85-17.84)$ & $2.25(1.5-4.0)$ & $93.30(64.4-142.9)$ & $10.7(8.4-14.9)$ \\
\hline
\end{tabular}

Data are geometric means (and range) or for $t_{\max }$ the median (and range)

$A U C_{0-\infty}$ area under the plasma concentration-time curve from 0 to infinity, $C_{\max }$ maximum plasma concentration, $n$ number of subjects, $t_{1 / 2}$ terminal elimination half-life, $t_{\max }$ time to reach $C_{\max }$

Table 4 Pharmacokinetic parameters of selexipag and ACT-333679 in healthy male subjects following multiple oral doses of selexipag in the fasted state

\begin{tabular}{|c|c|c|c|c|c|}
\hline Dose & $C_{\max }(\mathrm{ng} / \mathrm{ml})$ & $t_{\max }(\mathrm{h})$ & $\begin{array}{l}\operatorname{AUC}_{0-12 \mathrm{~h}}(\text { Day } 1) \text { or } \\
\operatorname{AUC}_{\tau}(\text { Day } 8)(\mathrm{ng} \cdot \mathrm{h} / \mathrm{ml})\end{array}$ & $t_{1 / 2}(\mathrm{~h})$ & $\begin{array}{l}\mathrm{AUC}_{\tau, \text { Day } ~} / \\
\mathrm{AUC}_{0-12 \mathrm{~h}, \text { Day } 1}\end{array}$ \\
\hline \multicolumn{6}{|l|}{ Selexipag } \\
\hline \multicolumn{6}{|l|}{$200 \mu \mathrm{g}$} \\
\hline Day $1(n=6)$ & $2.41(1.55-4.37)$ & $2.00(1.0-3.0)$ & $5.86(3.8-10.8)$ & $0.96(0.7-1.4)$ & NA \\
\hline Day $8(n=6)$ & $1.85(1.27-3.58)$ & $2.25(1.5-3.0)$ & $5.38(3.2-8.7)$ & $1.14(0.8-1.5)$ & $0.92(0.81-1.04)$ \\
\hline \multicolumn{6}{|l|}{$400 \mu \mathrm{g}$} \\
\hline Day $1(n=12)^{\mathrm{a}}$ & $4.34(2.14-7.55)$ & $2.50(1.5-4.0)$ & $11.04(5.8-15.6)$ & $1.28(0.7-1.8)$ & NA \\
\hline Day $8(n=6)$ & $4.12(2.68-5.64)$ & $2.26(1.0-3.0)$ & $9.70(7.4-12.5)$ & $1.41(1.2-1.9)$ & $0.79(0.56-1.12)$ \\
\hline \multicolumn{6}{|l|}{$600 \mu \mathrm{g}$} \\
\hline Day $8(n=6)$ & $5.29(3.14-7.03)$ & $2.00(1.0-4.0)$ & $13.78(10.8-17.8)$ & $1.24(0.7-2.5)$ & \\
\hline \multicolumn{6}{|l|}{ ACT-333679 } \\
\hline \multicolumn{6}{|l|}{$200 \mu \mathrm{g}$} \\
\hline Day $1(n=6)$ & $3.45(2.62-4.25)$ & $4.00(4.0-4.1)$ & $17.65(12.4-23.1)$ & $11.97(11.1-13.2)$ & NA \\
\hline Day $8(n=6)$ & $3.29(2.39-5.50)$ & $4.00(3.0-4.0)$ & $22.38(15.5-34.5)$ & $14.22(11.2-19.9)$ & $1.27(1.07-1.51)$ \\
\hline \multicolumn{6}{|l|}{$400 \mu \mathrm{g}$} \\
\hline Day $1(n=12)^{\mathrm{a}}$ & $5.92(3.54-10.13)$ & $4.00(3.0-4.0)$ & $27.90(17.1-47.0)$ & $10.46(8.7-13.6)$ & NA \\
\hline Day $8(n=6)$ & $4.69(3.68-8.55)$ & $4.00(2.0-4.0)$ & $29.28(23.8-51.2)$ & $13.72(10.8-15.9)$ & $1.02(0.84-1.15)$ \\
\hline \multicolumn{6}{|l|}{$600 \mu \mathrm{g}$} \\
\hline Day $8(n=6)$ & $8.72(6.72-10.06)$ & $4.00(3.0-4.0)$ & $46.86(35.7-58.4)$ & $10.53(8.5-14.7)$ & NA \\
\hline
\end{tabular}

Data are geometric means (and range) or for $t_{\max }$ the median (and range)

$A U C_{\tau}$ area under the plasma concentration-time curve during a dose interval, $A U C_{0-12 h}$ area under the plasma concentration-time curve from 0 to $12 \mathrm{~h}, C_{\max }$ maximum plasma concentration, $n$ number of subjects, $N A$ not applicable, $t_{1 / 2}$ terminal half-life, $t_{\max }$ time to reach maximum plasma concentration

${ }^{a} n=12$ comprising six subjects in the $400 \mu \mathrm{g}$ dose group and six in the 400/600 $\mu \mathrm{g}$ dose group. In the $400 / 600 \mu \mathrm{g}$ dose group, subjects received $400 \mu \mathrm{g}$ selexipag on Day 1

of selexipag and its metabolite on Day 1 in all dose groups are shown in Fig. 2. Selexipag plasma concentrations declined rapidly, and no subject who received active drug had plasma concentrations detectable beyond $16 \mathrm{~h}$. The elimination of selexipag was characterized by a mean terminal half-life varying between 0.7 and $2.3 \mathrm{~h}$ in the 

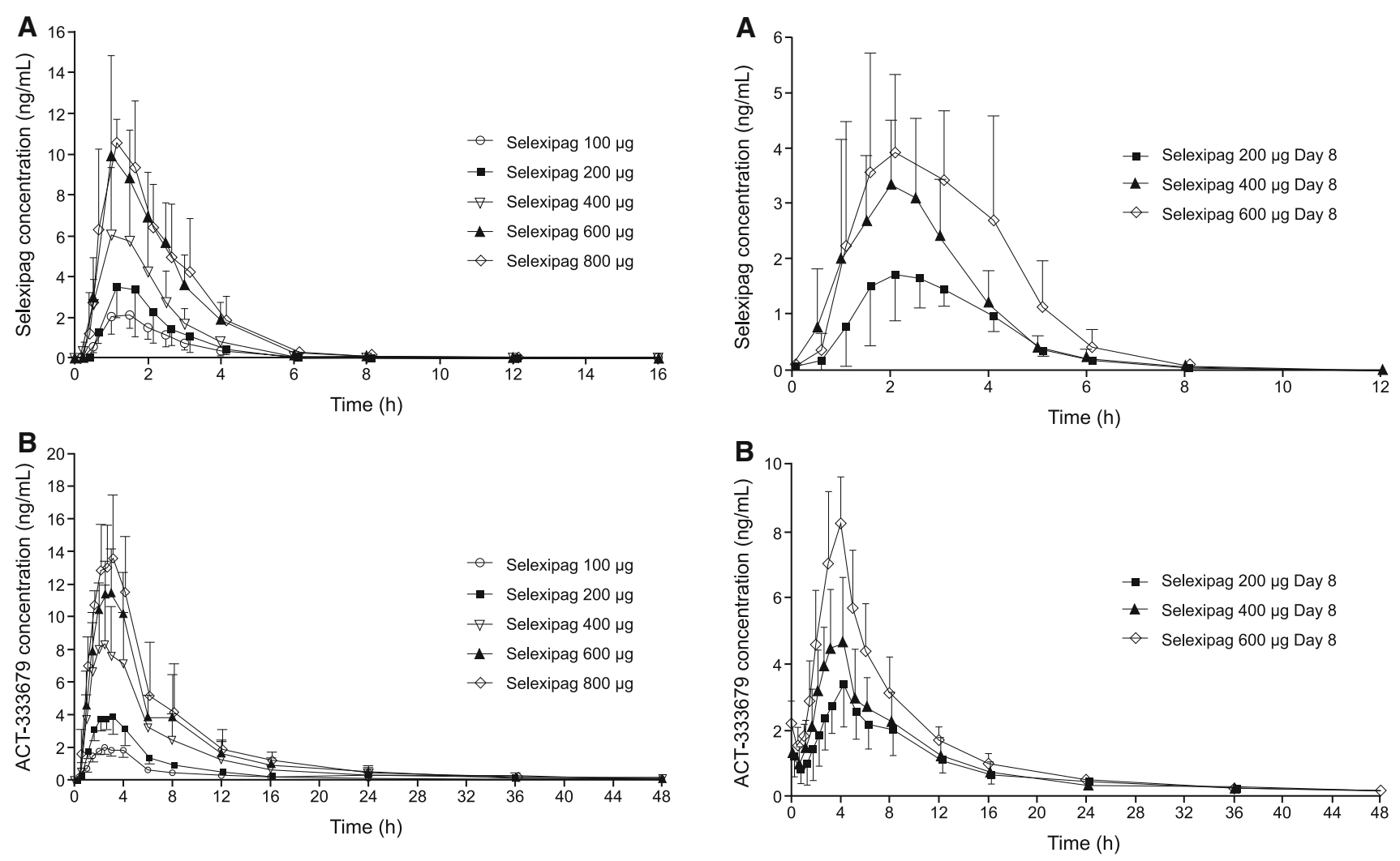

Fig. 2 Mean (standard deviation) plasma concentration-time profiles of selexipag (a) and ACT-333679 (b) after a single dose in healthy male subjects by dose group on Day 1 ( $n=6$ per dose group) in the fasted state

different dose groups. The maximum plasma concentrations of the metabolite were achieved between 2.25 and $2.75 \mathrm{~h}$ post-dose, with no concentration above $17.84 \mathrm{ng} /$ $\mathrm{ml}$. The terminal half-life of ACT-333679 was longer than that of selexipag, with means of between 9.4 and $12.6 \mathrm{~h}$ in the different dose groups. The exposure to ACT-333679 was approximately fourfold higher than with selexipag. Analysis of the data for dose proportionality showed that the $95 \%$ CI of selexipag and ACT-333679 for the slope included 1 for both $C_{\max }$ and $\mathrm{AUC}_{0-\infty}$, suggesting an approximate dose-proportional increase in both parameters across the doses tested (data not shown).

In the presence of food, the mean $\mathrm{AUC}_{0-\infty}$ for selexipag and ACT-333679 was, on average, $10 \%$ higher and $27 \%$ lower, respectively, whereas the median time to $C_{\max }$ increased from 1.00 and $2.50 \mathrm{~h}$ in the fasted state to 2.75 and $4.00 \mathrm{~h}$ in the fed state, respectively. The ratios of geometric means $(90 \% \mathrm{CI})$ for fed/fasted conditions for $C_{\max }$ were $0.65(0.48-0.88)$ and for $\mathrm{AUC}_{0-\infty} 1.10(0.92-1.30)$ for selexipag and $0.52(0.41-0.65)$ and $0.73(0.65-0.81)$ for the active metabolite, respectively.

The mean plasma concentration-time profiles of selexipag and its metabolite on Day 8 after multiple-dose

Fig. 3 Mean plasma concentration-time profiles after multiple dosing of selexipag (a) and ACT-333679 (b) in healthy male subjects by dose group on Day $8(200 \mu \mathrm{g}, 400 \mu \mathrm{g}$, and $600 \mu \mathrm{g})(n=6$ per dose group); in the fed state

administration in all dose groups are shown in Fig. 3. The observed and calculated PK variables on Day 1 and 8 for both parent compound and metabolite are shown in Table 2. The accumulation factors for selexipag, as estimated by the geometric mean ratio of $\mathrm{AUC}_{\tau}$ on Day 8 and $\mathrm{AUC}_{0-12 \mathrm{~h}}$ on Day 1 were 0.92 and 0.79 after 200 and $400 \mu \mathrm{g}$, respectively. The accumulation factors for ACT333679 were 1.27 and 1.02 after 200 and $400 \mu \mathrm{g}$ selexipag, respectively. Based on visual inspection of the mean trough concentrations of selexipag and ACT-333679, concentrations on Day 8 were at steady state (data not shown). The results of the dose-proportionality testing for selexipag using the power model assessment of Day $8 \mathrm{AUC}_{\tau}$ and $C_{\max }$ versus dose indicated a slope $(95 \% \mathrm{CI})$ of 0.85 (0.59-1.12) and $0.98(0.61-1.34)$, respectively. The $95 \%$ CI for both variables included 1, indicating dose-proportional PK of selexipag in the dose range tested. For ACT333679 , the results of the power model assessments showed that the slope and the $95 \% \mathrm{CI}$ were 0.85 (0.51-1.18) and $0.64(0.31-0.97)$ for $C_{\max }$ and $\mathrm{AUC}_{\tau}$, respectively. This indicates a dose-proportional increase in rate of exposure and a slight deviation from dose proportionality in extent of exposure to the active metabolite. 


\subsection{Urine Pharmacokinetics}

Selexipag could not be detected in urine, whereas ACT333679 was detected for doses of $200 \mu \mathrm{g}$ and higher. The active metabolite was mainly excreted during the first $12 \mathrm{~h}$ after dose, and the total amount excreted increased with increasing selexipag doses. The fraction of the administered selexipag dose excreted as ACT-333679 in urine was below $0.12 \%$ for all dose groups.

\section{Discussion}

Overall, single doses of selexipag given after overnight fasting were well tolerated at the 100, 200, and $400 \mu \mathrm{g}$ dose levels. Single doses of selexipag were less well tolerated at the 600 and $800 \mu \mathrm{g}$ dose levels due to increasing incidence and severity of AEs such as headache, nausea, dizziness, and vomiting. Multiple doses of selexipag were well tolerated at the $200 \mu \mathrm{g}, 400 \mu \mathrm{g}$, and 400/600 $\mu \mathrm{g}$ twice daily dose levels. Interestingly, flushing, a relatively common side effect of intravenous epoprostenol [11, 20], was not reported by any subject receiving selexipag. Likewise, no symptomatic hypotension was reported.

A dosing regimen of $600 \mu \mathrm{g}$ selexipag twice daily was well tolerated during the MAD part of the study following up-titration from $400 \mu \mathrm{g}$, whereas $600 \mu \mathrm{g}$ selexipag as a single dose without prior up-titration was less well tolerated following a single dose in the SAD study. This suggests improved tolerability after repeated dosing. Gradual dose up-titration is a common treatment regimen for drugs addressing the prostacyclin pathway, including epoprostenol (IV), treprostinil (oral, IV, subcutaneous, and inhaled), and iloprost (inhaled), which leads to individualized dosing for each patient based on the symptoms of the disease and tolerability of IP receptor agonists [21, 22]. This is of particular relevance as a clinical study on a subcutaneously administered prostacyclin analog suggested that patients who tolerate a higher dose of these drugs achieve greater improvement in disease markers such as exercise capacity [23].

Based on AUC and $C_{\max }$, the pharmacokinetics of selexipag were dose proportional over the tested dose range after single- and multiple-dose administration. Overall, after single- and multiple-dose administration, the plasma concentration-time profiles of selexipag were characterized by fast absorption (time to $C_{\max }\left[t_{\max }\right]$ approximately $1 \mathrm{~h}$ after drug administration) and an apparent mean elimination half-life of $0.7-2.3 \mathrm{~h}$ in the different dose groups. The active metabolite ACT-333679 is rapidly formed and more slowly eliminated, with a mean elimination half-life of 9.4-14.2 $\mathrm{h}$. These data are comparable to those obtained in a previous single-dose study [17].
The apparent dose-dependent increase in half-life could be explained by a longer time period above LLOQ and enabled capturing the actual elimination phase at higher doses that was not detectable at lower doses. The low urinary concentrations of unchanged selexipag or ACT333679 indicate that this compound is mainly eliminated via the hepatobiliary route, but urinary excretion of other metabolites cannot be excluded.

Exposure to the metabolite exceeded that of the parent compound by a factor of approximately four. As ACT333679 is a more potent IP receptor agonist in both receptor affinity and functional assays [17, 24], it is expected to be the major contributor to the pharmacological activity of selexipag. Within the multiple-dose regimen, no accumulation was measured in plasma on Day 8. Steady-state conditions had been attained within 8 days of twice-daily dosing. The observed PK profile of selexipag and its metabolite is consistent with twice-daily oral dosing, which is a regimen that has resulted in good patient compliance when compared with more frequent dosing regimens [25] or with other routes of administration [26, 27].

Compared with the fasted state, food decreased the rate of absorption of selexipag, shown by a decrease in $C_{\max }$ and a delay in median $t_{\max }$. Food had no significant effect on the extent of exposure to selexipag, whereas exposure to the active metabolite was reduced by $27 \%$; however, with the sample size chosen for this exploratory study, the lower or upper limits of the $90 \% \mathrm{CI}$ for $C_{\max }$ of selexipag and AUC and $C_{\max }$ of ACT-333679 were not within the limits for absence of a food effect. It is interesting to note that more subjects reported AEs in the fasted period ( $45 \%$ of subjects) than in the fed period (17\% of subjects), suggesting better tolerability when selexipag is administered with food.

\section{Conclusion}

Data from the SAD and MAD studies of selexipag show single oral doses of up to $400 \mu \mathrm{g}$ selexipag and twice-daily multiple oral doses of $600 \mu \mathrm{g}$ following up-titration from $400 \mu \mathrm{g}$ selexipag were well tolerated by healthy male subjects. Tolerability was improved following an up-titration scheme. The PK profile supports twice-daily dosing taken with food. Further investigations to achieve higher dose levels following an up-titration regimen are warranted.

Acknowledgments The authors thank apothecom scopemedical Ltd for editorial assistance and Shin Nippon Biomedical Laboratories Ltd for bioanalytical services. This study was sponsored by Nippon Shinyaku Co. Ltd.

Author contributions Tetsuhiro Yamada, Kaori Okubo, and Hideya Mukai contributed to study design and data analysis. Tim Mant performed the research. Initial manuscript preparation was carried out by Priska Kaufmann. Revision of manuscript and approval was conducted 
by Kaori Okubo, Shirin Bruderer, Tim Mant, Tetsuhiro Yamada, Jasper Dingemanse, Hideya Mukai, and Priska Kaufmann.

Conflicts of interest At the time of study conduct, Kaori Okubo, Tetsuhiro Yamada, and Hideya Mukai were employees of Nippon Shinyaku Co. Ltd. At the time of reporting, Priska Kaufmann, Shirin Bruderer, and Jasper Dingemanse were employees of and received stock options for Actelion Pharmaceuticals Ltd. Tim Mant is an employee of Quintiles, which conducted the study. Tim Mant is supported by the National Institute for Health Research (NIHR) Biomedical Research Centre at Guy's and St Thomas' NHS Foundation Trust and King's College London.

Ethical statement The protocol was approved by the Research Ethics Committee at St Thomas' Hospital (London, UK). Written informed consent was obtained from all subjects. The study was conducted in full compliance with the principles of the Declaration of Helsinki and with laws and regulations of the UK, where the research study was conducted. The Medicine and Health Care Products Regulatory Agency (MHRA) of the UK reviewed and approved the study before any activity was started.

Open Access This article is distributed under the terms of the Creative Commons Attribution Noncommercial License which permits any noncommercial use, distribution, and reproduction in any medium, provided the original author(s) and the source are credited.

\section{References}

1. Humbert M, Nunes H, Sitbon O, Parent F, Hervé P, Simmoneau G. Risk factors for pulmonary arterial hypertension. Clin Chest Med. 2001;22:459-75.

2. Schermuly RT, Ghofrani HA, Wilkins MR, Grimminger F. Mechanisms of disease: pulmonary arterial hypertension. Nat Rev Cardiol. 2011;8:443-55.

3. Delcroix M, Spaas K, Quarck R. Long-term outcome in pulmonary arterial hypertension: a plea for earlier parenteral prostacyclin therapy. Eur Respir Rev. 2009;18:253-9.

4. O'Callaghan DS, Humbert M. A critical analysis of survival in pulmonary arterial hypertension. Eur Respir Rev. 2012;21:218-22.

5. Pulido T, Adzerikho I, Channick RN, Delcroix M, Galiè N, Ghofrani HA, Jansa P, Jing ZC, Le Brun FO, Mehta S, Mittelholzer CM, Perchenet L, Sastry BK, Sitbon O, Souza R, Torbicki A, Zeng X, Rubin LJ, Simmoneau G. Macitentan and morbidity and mortality in pulmonary arterial hypertension. N Engl J Med. 2013;369:809-18.

6. Christman BW, McPherson CD, Newman JH, King GA, Bernard GR, Groves BM, Loyd JE. An imbalance between the excretion of thromboxane and prostacyclin metabolites in pulmonary hypertension. N Engl J Med. 1992;327:70-5.

7. Badesch DB, McLaughlin VV, Delcroix M, Vizza CD, Olschewski H, Sitbon O, Barst RJ. Prostanoid therapy for pulmonary arterial hypertension. J Am Coll Cardiol. 2004;43(12 suppl S):56S-61S.

8. Galiè N, Negro L, Simonneau G. The use of combination therapy in pulmonary arterial hypertension: new developments. Eur Respir Rev. 2009;18:148-53.

9. Hassoun PM, Mouthon L, Barberà JA, Eddahibi S, Flores SC, Grimminger F, Jones PL, Maitland ML, Michelakis ED, Morrell NW, Newman JH, Rabinovitch M, Schermuly R, Stenmark KR, Voelkel NF, Yuan JX, Humbert M. Inflammation, growth factors, and pulmonary vascular remodeling. J Am Coll Cardiol. 2009; 54(1 suppl):S10-9.
10. Sitbon O, Morrell N. Pathways in pulmonary arterial hypertension: the future is here. Eur Respir Rev. 2012;21:321-7.

11. Barst RJ, Rubin LJ, Long WA, McGoon MD, Rich S, Badesch DB, Groves BM, Tapson VF, Bourge RC, Brundage BH, Koerner SK, Langleben D, Keller CA, Murali S, Uretsky BF, Clayton LM, Jöbsis MM, Blackburn SD, Shortino D, Crow JW. A comparison of continuous intravenous epoprostenol (prostacyclin) with conventional therapy for primary pulmonary hypertension. N Engl J Med. 1996;334:296-301.

12. Galiè N, Manes A, Branzi A. Prostanoids for pulmonary arterial hypertension. Am J Respir Med. 2003;2:123-37.

13. Skoro-Sajer N. Optimal use of treprostinil in pulmonary arterial hypertension: a guide to the correct use of different formulations. Drugs. 2012;72:2351-63.

14. McLaughlin VV, Shillington A, Rich S. Survival in primary pulmonary hypertension: the impact of epoprostenol therapy. Circulation. 2002;106:1477-82.

15. Sitbon O, Humbert M, Nunes H, Parent F, Garcia G, Hervé P, Rainisio M, Simmoneau G. Long-term intravenous epoprostenol infusion in primary pulmonary hypertension: prognostic factors and survival. J Am Coll Cardiol. 2002;40:780-8.

16. Mubarak KK. A review of prostaglandin analogs in the management of patients with pulmonary arterial hypertension. Respir Med. 2010;104:9-21.

17. Kuwano K, Hashino A, Asaki T, Hamamoto T, Yamada T, Okubo K, Kuwabara K. 2-[4-[(5,6-Diphenylpyrazin-2-yl)(isopropyl) amino]butoxy]- $N$-(methylsulfonyl)acetam ide (NS-304), an orally available and long-acting prostacyclin receptor agonist prodrug. J Pharmacol Exp Ther. 2007;322:1181-8.

18. U.S. Department of Health and Human Services Food and Drug Administration Center for Drug Evaluation and Research (CDER). Guidance for Industry-Food-Effect Bioavailability and Fed Bioequivalence Studies. December 2002. http://www.fda. gov/downloads/RegulatoryInformation/Guidances/UCM126833. pdf. Accessed 29 Sept 2014.

19. Gough K, Hutchison M, Keene O, Byrom B, Ellis S, Lacey L, McKellar J. Assessment of dose proportionality: report from the statisticians in the pharmaceutical industry/pharmacokinetics UK joint working party. Drug Inf J. 1995;29:1039-48.

20. Naeije R, Huez S. Expert opinion on available options treating pulmonary arterial hypertension. Expert Opin Pharmacother. 2007;8:2247-65.

21. McLaughlin VV, Palevsky HI. Parenteral and inhaled prostanoid therapy in the treatment of pulmonary arterial hypertension. Clin Chest Med. 2013;34:825-40.

22. Skoro-Sajer N, Lang I, Naeije R. Treprostinil for pulmonary hypertension. Vasc Health Risk Manag. 2008;4:507-13.

23. Simonneau G, Barst RJ, Galiè N, Naeije R, Rich S, Bourge RC, Keogh A, Oudiz R, Frost A, Blackburn SD, Crow JW, Rubin LJ. Continuous subcutaneous infusion of treprostinil, a prostacyclin analogue, in patients with pulmonary arterial hypertension: a double-blind, randomized, placebo-controlled trial. Am J Respir Crit Care Med. 2002;165:800-4.

24. Morrison K, Studer R, Ernst R, Haag F, Kauser K, Clozel M. Differential effects of Selexipag [corrected] and prostacyclin analogs in rat pulmonary artery. $J$ Pharmacol Exp Ther. 2012;343:547-55.

25. Eisen SA, Miller DK, Woodward RS, Spitznagel E, Przybeck TR. The effect of prescribed daily dose frequency on patient medication compliance. Arch Intern Med. 1990;150:1881-4.

26. Jin J, Sklar GE, Min Sen Oh V, Chuen Li S. Factors affecting therapeutic compliance: a review from the patient's perspective. Ther Clin Risk Manag. 2008;4:269-86.

27. Kelloway JS, Wyatt R, DeMarco J, Adlis S. Effect of salmeterol on patients' adherence to their prescribed refills for inhaled corticosteroids. Ann Allergy Asthma Immunol. 2000;84:324-8. 